\title{
Discrepancies in reported versus measured nicotine content of e-cigarette refill liquids across nine European countries before and after the implementation of the EU Tobacco Products Directive
}

\section{To the Editor:}

In recent years, the e-cigarette market across European countries has grown extensively [1, 2], as $15 \%$ of Europeans report having tried e-cigarettes, representing a 7.0\% increase since 2012 [3]. E-cigarettes are regulated across the 28 European Union (EU) member states [4] under Article 20 of the Tobacco Products Directive (TPD), a legislative document which aims to regulate the internal European market and to harmonise the safety and quality of e-cigarette products through design specifications, including, but not limited to the volume of the refill container, nicotine content and the existence of child-resistant refill containers, among other parameters. In order for e-cigarette refill vials to be placed onto the market under the TPD, e-cigarettes must deliver nicotine doses at consistent levels under normal conditions of use (Art20;3f); must not contain $>20 \mathrm{mg} \cdot \mathrm{mL}^{-1}$ nicotine (Art20;3b); and only ingredients of high purity are to be used in the manufacture of the nicotine-containing liquid (Art20;3d) [4]. Research performed before the TPD was implemented indicated that there were wide inconsistencies between the labelled and the actual nicotine concentration of the products, with production impurities commonly noted [5-9].

In light of the above we aimed to evaluate potential impurities and the discrepancy between the reported and the measured nicotine concentration of the most popular brands of e-cigarette refill liquids in nine EU member states in order to assess whether the implementation of the TPD has led to an improvement in production quality and standards of e-cigarette refill liquids.

Within the context of a European Respiratory Society project, EUREST-PLUS, funded by the European Commission Horizon 2020 programme, we sampled the most popular e-cigarette refill liquids from nine EU member states (France, Poland, Germany, the Netherlands, United Kingdom, Spain, Romania, Hungary and Greece) at two time intervals, once before (pre-TPD, early 2016) and once after (post-TPD, early 2018) the implementation of the EU TPD [10]. At baseline (pre-TPD), Euromonitor reports on sales data were used to identify the top-selling companies in each EU member state. For two EU member states (the Netherlands and Romania) the 2016 Euromonitor report did not contain detailed data regarding the top-selling e-liquids and hence the top-selling companies were identified based on ALEXA rankings (website traffic rankings) as a proxy of their popularity in that national market. After identifying the "top five" selling companies in each EU member state, we randomly selected three products from each top-selling company ( 15 products from each of the nine EU member states $(n=135)$, of which $n=122$ were available for purchase).

Close monitoring of the nicotine concentration of e-cigarette refills in the $\mathrm{EU}$ is necessary, as discrepancies exist between the actual nicotine content in the vial as compared to that stated on the label, even after the implementation of the TPD http://bit.ly/33kqMbZ

Cite this article as: Girvalaki C, Tzatzarakis M, Vardavas A, et al. Discrepancies in reported versus measured nicotine content of e-cigarette refill liquids across nine European countries before and after the implementation of the EU Tobacco Products Directive. Eur Respir J 2020; 55: 1900941 [https://doi.org/ 10.1183/13993003.00941-2019]. 
In the post TPD phase, using only Euromonitor 2018 sales reports, we identified 107 matching products still on the market and included 30 new products that now represented products randomly selected from new companies in the top five in 2018. In total, 259 products were purchased. From the analysis we excluded four samples from the pre-TPD phase, as the content of nicotine was not reported on the vial, while we did not further assess three samples from the post-TPD phase in which zero nicotine was reported, and traces were detected. A discrepancy threshold was applied to take into account potential nicotine degradation post-production, based on both the European Commission Joint Research Centre (JRC) report $( \pm 10 \%)$ and the draft of the technical committee of the European Committee for Standardization electronic cigarettes and e-liquids (CEN TC437) [11, 12]. The latter sets a discrepancy level at $\pm 15 \%$ for liquids with a nicotine concentration of $0.50-5.99 \mathrm{mg} \cdot \mathrm{mL}^{-1}$, at $\pm 10 \%$ for concentrations of $6.00-12.99 \mathrm{mg} \cdot \mathrm{mL}^{-1}$ and $\pm 7 \%$ for concentrations $13.00-20.00 \mathrm{mg} \cdot \mathrm{mL}^{-1}$.

In total, 252 e-liquid refills were analysed for their concentrations of nicotine, nitrosamine and polycyclic aromatic hydrocarbon (PAH) content was performed using gas chromatography-mass spectrometry and liquid chromatography-mass spectrometry [13].

Our results indicated differences between the measured versus reported nicotine content in both the pre-TPD and post-TPD evaluation. Overall, more than half of the top-selling products in the EU market were measured to have a discrepancy in nicotine concentration that was greater than $\pm 10 \%$ of the amount labelled on the product (figure 1); an indicator of the lack of quality control in production of e-cigarette refill liquids [11]. From the 118 products of the pre-TPD phase, 57.6\% $(n=68)$ were above the threshold of $10 \%$ in nicotine discrepancy, while from the 134 products of the post-TPD phase, $53.7 \%(\mathrm{n}=72)$ were above the threshold of $10 \%$ noted by the JRC report. Only one product exceeded the legislated limit of
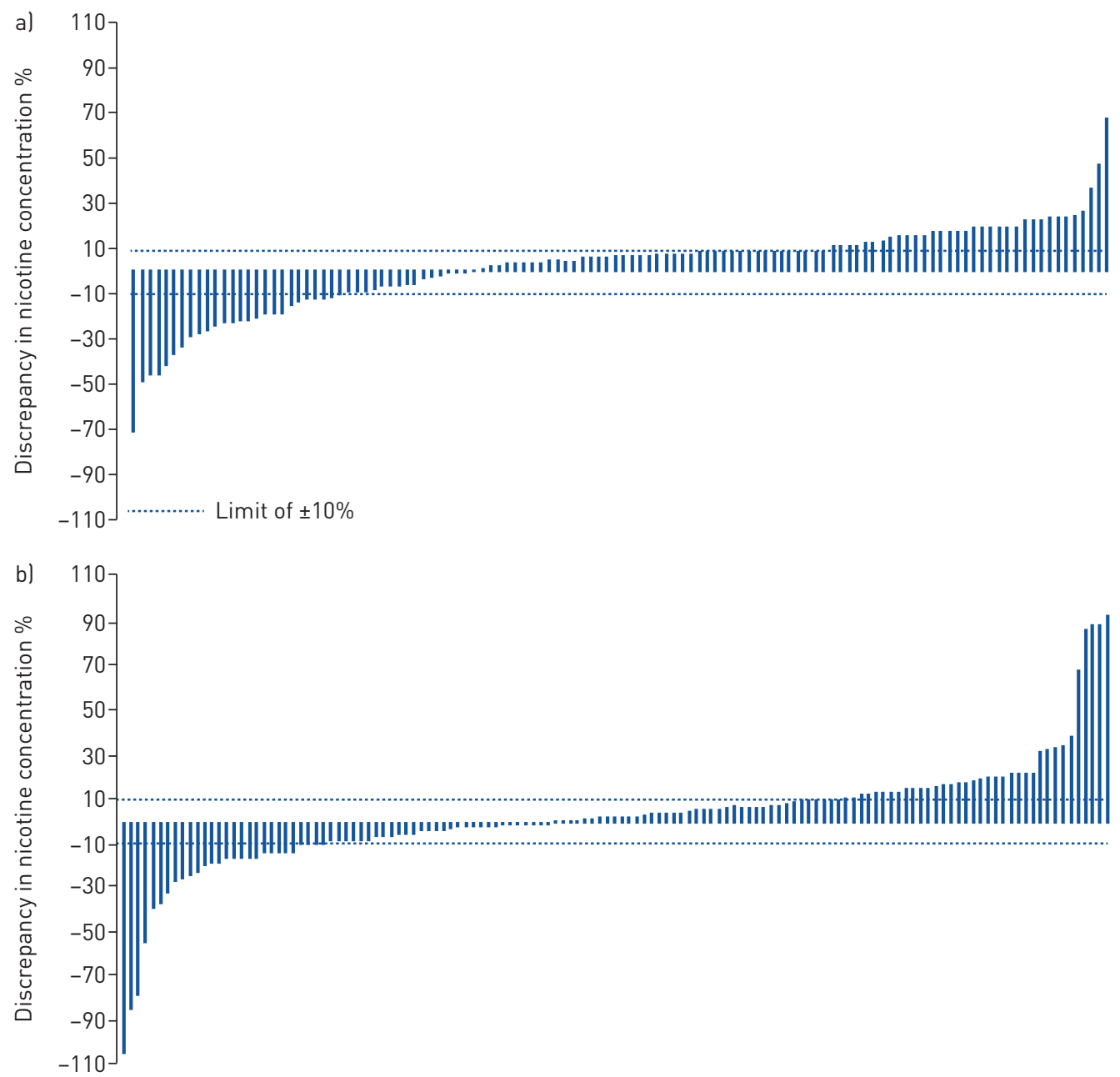

FIGURE 1 Discrepancies in the measured versus reported nicotine concentration among popular e-cigarette refill liquids across nine European Union member states a) before and b) after the implementation of the Tobacco Products Directive. 
$\leqslant 20 \mathrm{mg} \cdot \mathrm{mL}^{-1}$ of nicotine in the post-TPD phase in comparison to eight samples in the pre-TPD implementation.

Applying the CEN TC437 thresholds, for samples with a nicotine concentration $<5.99 \mathrm{mg} \cdot \mathrm{mL}^{-1}$, there was an increase in discrepancy (50\% pre-TPD versus $81.8 \%$ post-TPD). For samples with a nicotine concentration $6.00-12.99 \mathrm{mg} \cdot \mathrm{mL}^{-1}$ and samples with a nicotine concentration $13.00-20.00 \mathrm{mg} \cdot \mathrm{mL}^{-1}$ there was a slight decrease in discrepancy (59.7\% versus $50.6 \%$ and $71.0 \%$ versus $60.9 \%$, respectively)

Moreover, all products in both the pre- and post-TPD phase tested negative for nitrosamines and PAHs, indicating an absence of impurities, contrary to earlier research which had led to concerns related to the production and quality control process of these substances, hence indicating that improvements in quality control should now focus primarily on nicotine concentrations $[14,15]$.

Our findings are greater than those identified through pilot research performed by the European Commission JRC, which identified a discrepancy in almost one in three products among 39 EU refill liquids, lower than the discrepancy of $57.6 \%$ in our study; however, our sampling and sample size was extensively larger (255 e-liquids versus 39) [11]. This is the first assessment of discrepancies in nicotine content within e-cigarette refill liquids across multiple EU member states before and after implementation of the TPD using data from the most popular brands across the EU member states $(n=255)$, which would have the largest impact on consumers. However, as we tested only a randomly selected sample of the most popular e-liquids and we were not able to test all liquids available in Europe, our results may not be generalisable to the entire EU market, only the nine selected EU member states.

Our findings indicate the need for close monitoring of the nicotine concentration of electronic cigarette refills marketed in the EU, as discrepancies exist between the nicotine content in the vial and that stated on the label, even after the implementation of the TPD. These observed discrepancies may impact consumers by leading to a higher or lower nicotine uptake, which could impact their real or perceived level of addiction.

As mandated in the TPD, products that do not meet the strict quality criteria set under the Directive and "are not safe or are not of good quality or are otherwise not in conformity with this Directive" are subject to corrective actions, as manufacturers should "bring the product concerned into conformity with this Directive, to withdraw or to recall it, as appropriate" [4]. In light of the above, improvements in the production process and implementation of quality-control mechanisms for the nicotine content of e-cigarette refill vials in Europe are still needed, for the protection of consumer health.

Charis Girvalaki $\odot$, Manolis Tzatzarakis, Alexander Vardavas, Christina N. Kyriakos $\odot$, Katerina Nikitara, Polychronis Stivaktakis, Aristidis Tsatsakis and Constantine Vardavas

Laboratory of Toxicology, Faculty of Medicine, University of Crete, Heraklion, Greece.

Correspondence: Constantine Vardavas, Laboratory of Toxicology, Faculty of Medicine, University of Crete, Heraklion, Greece. E-mail: vardavas@tobcontrol.eu

Received: 10 May 2019 | Accepted after revision: 26 Oct 2019

Conflict of interest: None declared.

Support statement: This work was supported by a grant from the European Commission (Horizon2020 HCO-6-2015; EUREST-PLUS: 681109; C. Vardavas). Funding information for this article has been deposited with the Crossref Funder Registry.

\section{References}

1 Filippidis FT, Laverty AA, Gerovasili V, et al. Two-year trends and predictors of e-cigarette use in 27 European Union member states. Tob Control 2017; 26: 98-104.

2 Zhu SH, Sun JY, Bonnevie E, et al. Four hundred and sixty brands of e-cigarettes and counting: implications for product regulation. Tob Control 2014; 23: Suppl. 3, iii3-iii9.

3 European Commission. Special Eurobarometer 458: Attitudes of Europeans Towards Tobacco and Electronic Cigarettes. European Union, 2017.ISBN 978-92-79-69104-1. http://ec.europa.eu/commfrontoffice/publicopinion/ index.cfm/Survey/getSurveyDetail/instruments/SPECIAL/surveyKy/2146 Date last accessed: May, 2019. Date last updated: May 2017.

4 European Commission. Tobacco Products Directive. Directive 2014/40/eu of the European Parliament and of the Council, 2014. https://ec.europa.eu/health//sites/health/files/tobacco/docs/dir_201440_en.pdf Date last accessed: May, 2019.

5 Kim S, Goniewicz M, Yu S, et al. Variations in label information and nicotine levels in electronic cigarette refill liquids in South Korea: regulation challenges. Int J Environ Res Public Health 2015; 12: 4859-4868.

6 Goniewicz ML, Gupta R, Lee YH, et al. Nicotine levels in electronic cigarette refill solutions: a comparative analysis of products from the U.S., Korea, and Poland. Int J Drug Policy 2015; 26: 583-588. 
7 Srbinoska M, Kavrakovski Z, Rafajlovska V, et al. Determined and declared nicotine content in refill liquids for electronic cigarettes marketed in North Macedonia. Arh Hig Rada Toksikol 2019; 70: 130-133.

8 Hahn J, Monakhova YB, Hengen J, et al. Electronic cigarettes: overview of chemical composition and exposure estimation. Tob Induc Dis 2014; 12: 23.

9 Goniewicz ML, Kuma T, Gawron M, et al. Nicotine levels in electronic cigarettes. Nicotine Tob Res 2013; 15: 158-166.

10 Vardavas C, Girvalaki C, Vardavas A, et al. Respiratory irritants in e-cigarette refill liquids across nine European countries: a threat to respiratory health? Eur Respir J 2017; 50: 1701698.

11 European Commission. Administrative Arrangement $N^{\circ} 34851$ between DG SANTE and DG JRC regarding the project Technical support to the implementation of the Tobacco Products Directive. European Union, 2018. JRC114627. https://ec.europa.eu/jrc/en Date last updated: 2018. Date last accessed: July, 2019.

12 Technical Committee of the European Standardization body for EC and e-liquids (CEN TC437). General principles and requirements for testing for quality and nicotine levels of e-liquids, 2015. https://standards.cen.eu/ index.html. https://standards.cen.eu/index.html

13 Kavvalakis MP, Stivaktakis PD, Tzatzarakis MN, et al. Multicomponent analysis of replacement liquids of electronic cigarettes using chromatographic techniques. J Anal Toxicol 2015; 39: 262-269.

14 Goniewicz ML, Knysak J, Gawron M, et al. Levels of selected carcinogens and toxicants in vapour from electronic cigarettes. Tob Control 2014; 23: 133-139.

15 Etter JF, Zäther E, Svensson S. Analysis of refill liquids for electronic cigarettes. Addiction 2013; 108: 1671-1679.

Copyright (CERS 2020 